correlation between seasonal changes and VAS pain score, nocturnal awakenings, TJC, and CRP.

Conclusion: Chronic inflammatory rheumatisms activity was higher in winter. Health care professionals should take seasonal changes into account in order to improve therapeutic care.

Disclosure of Interests: None declared

DOI: 10.1136/annrheumdis-2021-eular.412

\section{AB0887-HPR CHARLSON COMORBIDITY INDEX (CCI) IN RHEUMATOID ARTHRITIS: CLASSIFICATION AND CORRELATIONS}

C. Flourou ${ }^{1}$, S. Psarelis ${ }^{2}$, A. Tofarides ${ }^{3}$, E. Papanicolaou4, G. Papazisis ${ }^{5}$. ${ }^{1}$ Nicosia General Hospital, Internal Medicine Department, Nicosia, Cyprus; ${ }^{2}$ Nicosia General Hospital, Rheumatology Department, Nicosia, Cyprus; ${ }^{3}$ Nicosia General Hospital, Internal Medicine Department, Nicosia, Cyprus; ${ }^{1}$ Nicosia General Hospital, Internal Medicine Department, Nicosia, Cyprus: ${ }^{5}$ Aristotle University of Thessaloniki, Clinical Pharmacology, Thessaloniki, Greece

Background: Charlson Comorbidity Index[1] is a tool including age and chronic diseases assessing the comorbidity burden. The age and the comorbidity burden in RA patients determine the morbidity and mortality.

Objectives: To assess and classification of $\mathrm{CCl}$ in RA patients with usage of the health-care system (outpatient clinics) in a real-world setting.

Methods: 327 patients with RA from a large outpatient service of a central hospital were retrospectively reviewed. Demographic characteristics, treatment for RA and comorbidities were recorded. Charlson Comorbidity Index (CCl) was measured and classified as low, intermediate and high score for 1-2, 3-4 and $>=5$ points, respectively. Its correlation with polypharmacy and necessity of biologic DMARDs was studied. Univariable and multivariable analyses were performed.

Results: Data from 327 RA patients (75,8\% females, $24,2 \%$ males) with a mean $\pm S D$ age of $63 \pm 11,8$ years and disease duration $113 \pm 63$ months, were recorded.

$\mathrm{CCl}$ was $3 \pm 1,2$ points (mean $\pm \mathrm{SD}$ ) and maximum score was observed at 7 points. High score ( $>=5$ points) was observed at $9,2 \%$ and in the majority the score was intermediate (3-4points) at $55 \%$. All the RA patients with high score fulfilled the criteria of polypharmacy. Patients with high score had 9,7 times more probability of polypharmacy than the patients with low score $(p=0.09$, $1.4-2.595 \% \mathrm{Cl}$ ).

70 patients were treated with biologic-DMARDs $(21,7 \%)$, in the majority with TNFa inhibitors $(16,5 \%)$. In RA patients receiving biologic-DMARDs was observed low or intermediate score of $\mathrm{CCl}$. The most likely explanation is the severity of the disease that predominated, its complications and the possible overlap with other conditions.

Conclusion: The majority of RA patients had intermediate score of $\mathrm{CCl}$. In patients with high score-meaning more comorbidities- polypharmacy was observed completely. Patients receiving biologic-DMARDs characterized with less comorbidities.

REFERENCES:

[1] Charlson E M et al. A new method of classifying prognostic comorbidity in longitudinal studies:development and validation. J Chronic Dis. 1987;40(5):373-83

Disclosure of Interests: None declared

DOI: 10.1136/annrheumdis-2021-eular.1103

\section{AB0888-HPR EULAR SJOGREN'S SYNDROME PATIENT REPORTED INDEX-FATIGUE SCORE AND HADS-DEPRESSION SCORE MEDIATE IDENTITY SCORE OF ILLNESS PERCEPTION QUESTIONNAIRE IN PATIENTS WITH PRIMARY SJÖGREN'S SYNDROME}

A. Kapusuz ${ }^{1}$, K. Abacar ${ }^{2}$, Y. Yenisoy ${ }^{1}$, İ. Tatı ${ }^{3}$, E. N. Çakır ${ }^{1}$, F. Türe-Özdemir ${ }^{3}$, M. Yay ${ }^{4}$, Ü. Karaçaylı $I^{5}$, H. Direskeneli ${ }^{2}$, N. Inanc ${ }^{2}$, G. Mumcu ${ }^{6}{ }^{1}$ Marmara University, Institute of Health Sciences, Istanbul, Turkey; ${ }^{2}$ Marmara University Medical School, Department of Rheumatology, Istanbul, Turkey; ${ }^{3}$ Marmara University Medical School, Department of Heamatology and Immunology, Istanbul, Turkey; ${ }^{4}$ Mimar Sinan Fine Arts University, Department of Statistics, Istanbul, Turkey; ${ }^{5} \mathrm{Health}$ Sciences University, Department of Oral and Dental Surgery, Istanbul, Turkey; ${ }^{6}$ Marmara University, Department of Health Management, Istanbul, Turkey

Background: Dryness, fatigue, and pain are common clinical manifestations assessed by EULAR Sjogren's Syndrome Patient Reported Index (ESSPRI)-Dryness, -Fatigue, -Pain scores in patients with primary Sjögren's syndrome (pSS). In addition, depression is also seen in these patients owing to the pattern of the chronic disease.
Objectives: The aim of the study was to assess the complex interactions among Depression status, Illness Perception, and prominent clinical manifestations evaluated by the ESSPRI (Dryness, Fatigue, and Pain) in patients with pSS.

Methods: In this cross-sectional study, 111 patients with pSS (M/F: 5/106; mean age: $52.9 \pm 12.01$ years) were included. The data were collected by clinical examination and a questionnaire regarding patient reported outcome measures (PROMs). Unstimulated (U-WSFR) and stimulated (S-WSFR) whole saliva flow rates of patients were calculated as $\mathrm{ml} / \mathrm{min}$. Hospital Anxiety and Depression Scale (HADS), Illness Perception Questionnaire-R (IPQ-R) and EULAR Sjogren's Syndrome Patient Reported Index were filled by patients. Increases in HADS score and subgroup scores of ESSPRI (Dryness, Fatigue and Pain) and IPQ-R dimensions regarding Identity, Consequences, and Emotional reflected poor conditions for patients. In addition, patients scored their disease activity ( 0 : inactive-100: the worst activity) by using 100-mm visual analogue scale (VAS) After preliminary analysis, a mediation analysis was used to evaluate the relations among these variables.

Results: In the study, ESSPRI-Dryness score $(6,27 \pm 2,79)$ was associated with U-WSFR $(0,40 \pm 0,57)$ and S-WSFR $(1,04 \pm 0,86),(r:-0,4 p=0.000 ; r:-0,3 p=0.004)$ Moreover, patients reported disease activity score $(48,78 \pm 26,67)$ was related to U-WSFR ( $r:-0,3 p=0.026)$ as well as Consequence $(19,12 \pm 5,47)$ and Emotional $(19,54 \pm 7,02)$ scores of IPQ-R questionnaire ( $r: 0,3 p=0.035 ; r: 0,3 p=0.014)$. In IPQ-R questionnaire, Identity score $(8,04 \pm 3,1)$ reflecting number of symptoms that patients experienced due to their illness was correlated with scores of ESSPRI-Fatigue $(5,29 \pm 2,97)$, ESSPRI-Pain $(5,18 \pm 3,01)$, HADS-Anxiety $(11,67 \pm 5,55)$, HADS-Depression $(9,2 \pm 4,98)$ in the study $(p<0.05)$.

In the mediation analysis, Identity score was directly mediated by ESSPRI-Fatigue score $(p=0.0093)$ and indirectly mediated by HADS-Depression score $(p=0.0011)$

A bootstrap analysis with 5000 replications was applied to estimate mediation effect to generate $95 \% \mathrm{Cl}$. Percentile bootstrap of HADS-Depression was found to be an effective mediator for Identity score based on 5000 bootstrap sample. Conclusion: Both depression status and fatigue affected Identity score reflecting the number of symptoms poorly. Considering this complex relationship in disease activity assessment may positively affect disease outcomes.

Disclosure of Interests: None declared

DOI: 10.1136/annrheumdis-2021-eular.1893

\section{AB0889-HPR PERCEIVED SATISFACTION WITH CHRONIC PAIN CARE IN GERMAN PATIENTS WITH FIBROMYALGIA (FM)}

M. Offenbächer ${ }^{1}$, L. Toussaint ${ }^{2}$, J. Hirsch ${ }^{3}$, M. Weigl ${ }^{4}$, N. Kohls ${ }^{5}$, M. Vallejo ${ }^{6}$, J. Rivera ${ }^{7}$, F. Sirois ${ }^{8}$, J. Dezutter' ${ }^{1}{ }^{1}$ Gasteiner Heilstollen, Medical Department, Bad Gastein, Austria; ${ }^{2}$ Luther College, Psychology, Decorah, United States of America; ${ }^{3}$ East Tennessee State University, Psychology, Johnson City, United States of America; ${ }^{4}$ Klinikum Großhadern, Department of Orthopaedics, Physical Medicine and Rehabilitation, München, Germany; ${ }^{5}$ Coburg University of Applied Sciences, Health Promotion, Coburg, Germany; ${ }^{6}$ UNED, Psychology, Madrid, Spain; ${ }^{7}$ Gregorio Marañón Hospital, Rheumatology, Madrid, Spain; ${ }^{8}$ The University of Sheffield, Psychology, Sheffield, United Kingdom; ${ }^{9}$ University of Leuven, School Psychology and Development in Context, Leuven, Belgium

Background: In chronic pain care a multidimensional perspective with attention to patients' cognitions, emotions, and their ability to cope is needed (1) Previous studies are also pointing to the role of experiencing meaningfulness in life in the adjustment to disability. Therefore care should additionally focus on the existential domain of patients' lives to live up to a holistic care approach (2). However, there are only a few studies on how FM patients are satisfied with practitioners' attention to multiple aspects of life with a chronic pain condition. Objectives: To assess perceived satisfaction with chronic pain care and its associations with health variables in a cohort of patients with FM.

Methods: We invited 18 FM self-help groups in Germany to participate anonymously in our survey and sent them in total 192 paper-and-pencil surveys. Sociodemographics, disease related variables (e.g. pain, general health) and psychological variables [e.g. depression, anxiety, hope, stress] were assessed with standardized instruments, including 5 items (answer format $1=$ very unsatisfied $-10=$ very satisfied) assessing subjective satisfaction with medical care in different domains with the following questions: How satisfied are you with the attention of your treatment team/physician at home for physiological aspects of your pain (Physio)/ the consequences of the pain on your physical functioning (Physical)/ on your psychological well-being (Mental)/ on your social life (Social)/ on your meaning in life (Meaning).

Results: In total $162 \mathrm{FM}$ patients participated ( $=84 \%$ response rate). Their mean age was 58 years $(S D=10), 84 \%(N=135)$ were female. Highest level of education was: Elementary School 29\%, Junior High School 35\%, High School $15 \%$, College $12 \%$, and other $10 \%$. Duration of chronic pain was 
18.2 years $(S D=12.0)$. The satisfaction with care scale showed good internal consistency and measured one factor. The means of the subscale were: Physio $5.7(\mathrm{SD}=2.5) /$ Physical $5.5(\mathrm{SD}=2.5) /$ Mental $5.5(\mathrm{SD}=2.6)$ / Social 5.0 $(\mathrm{SD}=2.5) /$ Meaning $5.3(\mathrm{SD}=2.6)$. Correlations of the subscales are depicted in Table 1. There were no associations between pain variables and satisfaction with care, but satisfaction with care was associated with mental health, but not physical health, outcomes.

Table 1. Correlations of satisfaction of care with different health variables. Subscales physiological and physical aspects and HADS-anxiety were not significantly correlated. ${ }^{*}<.05 ;{ }^{* *}<.01$; ns=not significant.

\begin{tabular}{lcclcc}
\hline & Physio & Physical & Mental & Social & Meaning \\
\hline HADS-depression & $-.10(\mathrm{~ns})$ & $-.12(\mathrm{~ns})$ & $-.19^{\star}$ & $-.16^{\star}$ & $-.14(\mathrm{~ns})$ \\
General Health & $.02(\mathrm{~ns})$ & $.14(\mathrm{~ns})$ & $.13(\mathrm{~ns})$ & $.18^{*}$ & $.12(\mathrm{~ns})$ \\
Stress & $-.15(\mathrm{~ns})$ & $-.14(\mathrm{~ns})$ & $-.17^{\star}$ & $-.17^{\star}$ & $-.13(\mathrm{~ns})$ \\
Hope & $.18(\mathrm{~ns})$ & $.18(\mathrm{~ns})$ & $.26^{\star \star}$ & $.26^{*}$ & $.22^{\star}$
\end{tabular}

Conclusion: In this cohort of German FM patients the average satisfaction with care overall, as well as the specific aspects of care, was only moderate. Interestingly we found associations between satisfaction with care in mental, social and meaning in life aspects with psychological well-being pointing to the fact that care for chronic pain patients should also include those aspects in addition to just addressing biomedical aspects.

REFERENCES:

[1] Flor $\mathrm{H}$ and Turk D. Chronic pain: an integrated approach. Seattle, WA: IASP Press, 2011.

[2] Dezutter J, Casalin S, Wacholtz A, et al. Meaning in life: An important factor for the psychological well-being of chronically ill patients? Rehabilitat Psychol 2013; 58:334-341.

Disclosure of Interests: None declared

DOI: 10.1136/annrheumdis-2021-eular.1993

\begin{tabular}{|l|l}
\hline AB0890-HPR & THE IMPACT OF GENDER ON PHYSICAL \\
& FUNCTION, FATIGUE, LONELINESS, DEPRESSION, \\
& AND SEXUAL FUNCTIONING IN PATIENTS WITH \\
& RHEUMATOID ARTHRITIS WITH A SPECIAL FOCUS \\
& ON METHOTREXATE USAGE. A CROSS-SECTIONAL \\
& SINGLE-CENTRE STUDY
\end{tabular}

L. T. Bay ${ }^{1}$, D. S. Nielsen ${ }^{2}$, C. Flurey ${ }^{3}$, A. Giraldi ${ }^{4}$, S. Möller ${ }^{5}$, C. Graugaard ${ }^{6}$, T. Ellingsen $1 .{ }^{1}$ Odense University Hospital, Rheumatology Research Unit,
Department of Rheumatology, Odense, Denmark; ${ }^{2}$ Odense University Hospital, Migrant Health Clinic \& Department of Geriatrics, Odense, Denmark; ${ }^{3}$ University of the West of England, Faculty of Health and Applied Sciences, Bristol, United Kingdom; ${ }^{4}$ Copenhagen University, Sexological Clinic, Psychiatric Centre Copenhagen, Copenhagen, Denmark; ${ }^{5}$ Odense University Hospital \& University of Southern Denmark, OPEN, Odense, Denmark; ${ }^{6}$ Aalborg University, Center for Sexology Research, Aalborg, Denmark

Background: We lack knowledge of how gender, disease characterization, and measures of various Patient Reported Outcome Measures (PROMS) relate to Methotrexate (MTX) usage in patients with rheumatoid arthritis.

Objectives: To investigate the impact of gender on physical function, fatigue depression, loneliness, and sexual functioning with a special focus on MTX usage.

Methods: A cross-sectional study design was used to collect data in a rheumatologic outpatient clinic. The following PROMs were applied: Changes in Sexua Functioning Questionnaire, UCLA Loneliness Scale, Beck's Depression Inventory, Bristol Rheumatoid Arthritis Fatigue-Numeric Rating Scale, and the Health Assessment Questionnaire.

Results: Among 286 patients diagnosed with rheumatoid arthritis (69 men and 217 women), $67.8 \%$ were defined as MTX-users one year after diagnosis.

Comparing women and men we found differences in PROMS, with significantly worse outcomes for women than men in physical functioning at diagnosis and in sexual functioning, depression, fatigue, physical functioning, and patient evaluation of disease burden at enrolment in the study.

There were only significant differences in the HAQ and loneliness score when comparing MTX-users with MTX-non-users in general (Table 1).

Conclusion: The results of this study show that women have more negative outcomes on the selected PROMs compared to men with RA. This difference between genders was also evident when comparing MTX-users with non-MTXusers, again with a poorer outcome on PROMs for women compared to men. This calls for attention in the clinical setting and further research in the used instruments and the importance of gender in the care and treatment of patients with RA.

Disclosure of Interests: Laila Twisttmann Bay: None declared, Dorthe S. Nielsen: None declared, Caroline Flurey: None declared, Annamaria Girald Speakers bureau: Astellas, Paid instructor for: Payment for lectures, Astellas, Consultant of: Ovaco Bio,Palatin Technologies, Futura Medical, Sören Möller: None declared, Christian Graugaard: None declared, Torkell Ellingsen: None declared

DOI: 10.1136/annrheumdis-2021-eular.2039

Table 1. Second column is adjusted for gender, patient age, years of education, and living alone, all other columns are not adjusted for gender. HAQ Health Assessment Questionnaire, VAS Visual Analog Scale, UCLA University of California Los Angeles, CSFQ Changes in Sexual Functioning Questionnaire, BDI Becks Depression Inventory, BRAF-NRS Bristol Rheumatoid Arthritis Fatigue Numeric Rating Scale

\begin{tabular}{|c|c|c|c|c|c|c|c|c|c|c|c|c|}
\hline \multirow[t]{2}{*}{ Adjusted analyses } & \multicolumn{2}{|c|}{$\begin{array}{l}\text { Comparing Women and } \\
\text { men (overall) }\end{array}$} & \multicolumn{2}{|c|}{$\begin{array}{l}\text { Comparing MTX-users and } \\
\text { non-MTX-users (overall) }\end{array}$} & \multicolumn{2}{|c|}{$\begin{array}{l}\text { Comparing women and men } \\
\text { (MTX-user) }\end{array}$} & \multicolumn{2}{|c|}{$\begin{array}{l}\text { Comparing women and men } \\
\text { (non-MTX-users) }\end{array}$} & \multicolumn{2}{|c|}{$\begin{array}{l}\text { Comparing male } \\
\text { MTX-users and male } \\
\text { non-MTX-users }\end{array}$} & \multicolumn{2}{|c|}{$\begin{array}{l}\text { Comparing female } \\
\text { MTX-users and female } \\
\text { non-MTX-users }\end{array}$} \\
\hline & $\begin{array}{l}\text { Coefficient } \\
(95 \% \mathrm{Cl})\end{array}$ & p-value & $\begin{array}{l}\text { Coefficient } \\
(95 \% \mathrm{Cl})\end{array}$ & $p$-value & $\begin{array}{l}\text { Coefficient } \\
(95 \% \mathrm{Cl})\end{array}$ & $p$-value & $\begin{array}{l}\text { Coefficient } \\
(95 \% \mathrm{Cl})\end{array}$ & $p$-value & $\begin{array}{l}\text { Coefficient } \\
(95 \% \mathrm{Cl})\end{array}$ & $p$-value & $\begin{array}{l}\text { Coefficient } \\
(95 \% \mathrm{Cl})\end{array}$ & $p$-value \\
\hline \multicolumn{13}{|c|}{ Physical functioning at diagnosis } \\
\hline $\begin{array}{l}\mathrm{HAQ} \\
\text { Physical functioni }\end{array}$ & $\begin{array}{l}0.42(0.19 \\
0.66)\end{array}$ & $<0.001$ & $-0.31(-0.59 ;-0.04)$ & 0.024 & $0.30(0.04 ; 0.56)$ & 0.025 & $1.09(0.68 ; 1.51)$ & $<0.001$ & $0.25(-0.14 ; 0.64)$ & 0.205 & $-0.54(-0.84 ;-0.24)$ & $<0.001$ \\
\hline $\mathrm{HAQ}$ & $\begin{array}{l}0.38 \\
(0.20-0.55)\end{array}$ & $<0.001$ & $-0.13(-0.29-0.03)$ & 0.101 & $0.39(0.19-0.59)$ & $<0.001$ & $0.30(-0.07-0.66)$ & 0.112 & $-0.21(-0.57-0.16)$ & 0.274 & $-0.11(-0.30-0.07)$ & 0.216 \\
\hline \multicolumn{13}{|c|}{$\begin{array}{l}\text { PROMs at enrollment } \\
\text { Sexual dysfunction }\end{array}$} \\
\hline CSFQ & $\begin{array}{l}-12.16 \\
(-14.80--9.52)\end{array}$ & $<0.001$ & $-1.17(-3.76-1.41)$ & 0.374 & $-13.30(-16.27-10.33)$ & $<0.001$ & $-9.20(-14.90--3.49)$ & 0.002 & $1.99(-3.45-7.43)$ & 0.473 & $-2.11(-5.17-0.95)$ & 0.177 \\
\hline $\begin{array}{l}\text { Loneliness } \\
\text { UCLA }\end{array}$ & $\begin{array}{l}1.60(-1.35 \\
-4.54)\end{array}$ & 0.288 & $4.15(1.46-6.85)$ & 0.003 & $2.52(-0.93-5.98)$ & 0.153 & $0.37(-4.64-5.38)$ & 0.885 & $2.47(-2.68-7.61)$ & 0.347 & $4.62(1.50-7.73)$ & 0.004 \\
\hline $\begin{array}{l}\text { Depression } \\
\text { BDI }\end{array}$ & $\begin{array}{l}2.77(1.04 \\
-4.50)\end{array}$ & 0.002 & $1.79(-0.01-3.58)$ & 0.051 & $3.18(1.07-5.28)$ & 0.003 & $2.14(-0.50-4.78)$ & 0.112 & $0.98(-1.58-3.53)$ & 0.454 & $2.01(-0.15-4.18)$ & 0.068 \\
\hline $\begin{array}{l}\text { Fatigue } \\
\text { BRAF-NRS }\end{array}$ & & & & & & & & & & & & \\
\hline Severity & $\begin{array}{l}0.97(0.31 \\
-1.63)\end{array}$ & 0.004 & $0.40(-0.20-1.00)$ & 0.187 & $1.05(0.30-1.81)$ & 0.006 & $0.87(-0.50-2.25)$ & 0.212 & $0.26(-1.13-1.66)$ & 0.713 & $0.44(-0.24-1.12)$ & 0.201 \\
\hline Effect & $\begin{array}{l}1.06(0.39 \\
-1.72)\end{array}$ & 0.002 & $0.25(-0.38-0.88)$ & 0.442 & $1.07(0.28-1.86)$ & 0.008 & $1.10(-0.24-2.44)$ & 0.108 & $0.27(-1.08-1.63)$ & 0.694 & $0.24(-0.49-0.98)$ & 0.521 \\
\hline Coping & $\begin{array}{l}0.60 \\
(-0.09-1.28)\end{array}$ & 0.087 & $0.33(-0.33-0.99)$ & 0.329 & $0.93(0.13-1.72)$ & 0.022 & $-0.25(-1.78-1.28)$ & 0.749 & $-0.60(-2.17-0.98)$ & 0.457 & $0.58(-0.15-1.31)$ & 0.120 \\
\hline
\end{tabular}

